\title{
Somos plenamente libres. Las mujeres artistas y el surrealismo
}

\author{
Museo Picasso Málaga \\ Del 10 de octubre de 2017 al 28 de enero de 2018
}

En 1966 William Rubin intentó definir una posible teoría del estilo surrealista ante la enorme heterogeneidad de las propuestas de los miembros vinculados a este movimiento artístico. Para ello, planteó la existencia de dos grandes polos de origen freudiano. De una parte, el polo automatista/abstracto cuyo origen estaría vinculado a la asociación libre de ideas, y de otra, un polo académico/ilusionista fundamentado en la interpretación de los sueños. Esta propuesta de Rubin fue concretada dos años más tarde en la exposición Dada, Surrealism and their Heritage celebrada en el MoMA que, a pesar de su esfuerzo por explicar el legado surrealista, dejaba fuera del mismo a las mujeres artistas que participaron de un modo u otro en él. La lectura de Rubin partía a su vez del texto fundacional El surrealismo y la pintura publicado por André Breton en 1925. Por este motivo, observamos en la lectura de Rubin una indefinición del Surrealismo que el propio Breton no terminó de resolver.

Este tipo de lecturas fueron revisadas a partir de la década de 1970 por críticos vinculados a la revista October como Rosalind Krauss que señalaron la estrechez de miras que suponía plantear lecturas estilísticas de un movimiento tan heterogéneo. Krauss señaló que, más allá de la cuestión estilístico-formal, los verdaderos objetos creados por los surrealistas fueron las revistas, en las que el principal recurso visual es la fotografía.

De este modo, Krauss planteó una crítica a las lecturas de Breton y Rubin a partir de la importancia que le otorgaron los surrealistas a la fotografía ilustrativa y, como consecuencia, señaló la incapacidad de los conceptos estilísticos derivados de un código pictórico o formal para abordar estas creaciones artísticas. Dicho de otro modo, es en el código fotográfico y no en el pictórico donde hay que buscar las posibles definiciones del Surrealismo.

Esta orientación que plantea Rosalind Krauss coincide en el tiempo con el desarrollo de la crítica feminista de la historia del arte que, a partir de la década de 1970, plantea nuevas lecturas desde la perspectiva de género. En ese sentido, la pregunta inaugural de Linda Nochlin, «¿Por qué no ha habido grandes mujeres artistas?», fue respondida en la década de 1980 por el pionero estudio de Whitney Chadwick Women Artists and the Surrealist Movement en el que aborda el estudio de aquellas artistas que estuvieron de un modo $u$ otro vinculadas al Surrealismo. Y decimos vinculadas, y no plenamente surrealistas, ya que muchas de ellas rechazaron expresamente que las asociaran con el grupo de los surrealistas.

Es a partir de este contexto de la crítica feminista de la historia del arte como podemos enmarcar la exposición que el Museo Picasso Málaga ha presentado bajo el título Somos plenamente libres. Las mujeres artistas y el surrealismo. Con un total de 124 obras de 18 artistas la exposición plantea una revisión de la aportación de las mujeres artistas al movimiento surrealista. Comisariada por el catedrático de Estética y Teoría de las Artes de la Universidad Autónoma de Madrid José Jiménez, que ya comisarió en 2013 la exposición El surrealismo y el sueño para el Museo Thyssen-Bornemisza, la muestra incluye obras de artistas como Remedios Varo, Claude Cahun, Dora Maar, Maruja Mallo, Lee Miller, Leonor Fini, Leonora Carrington, Meret Oppenheim o Ángeles Santos. Además, esta muestra se enmarca en una larga serie de exposiciones realizadas por el Museo Picasso Málaga y dedicadas a artistas como Louise Bourgeois, Hilma af Klimt o Sophie Tauber-Arp.

En 1929 la psicoanalista Joan Rivière publicó La feminidad como mascarada donde abordó el estudio de aquellos sujetos, hombres y mujeres, que teniendo una posición heterosexual, mostraban rasgos homosexuales. A partir de esa hipótesis Rivière plantea que algunas mujeres que aspiran a una cierta masculinidad pueden adoptar la máscara de la femineidad para alejar la angustia y evitar la venganza que temen de parte del hombre. $Y$ es precisamente el cuestionamiento de la identidad, a través de la máscara y el espejo, el que abre la primera sección de la exposición en la que encontramos obras que abordan la poética de lo invisible como la radiografía de Meret Oppenheim. También encontramos las célebres fotografías de Claude Cahun en las que la artista muestra un rostro desdoblado por la presencia del espejo, a la vez que juega con la imagen andrógina y la construcción del 


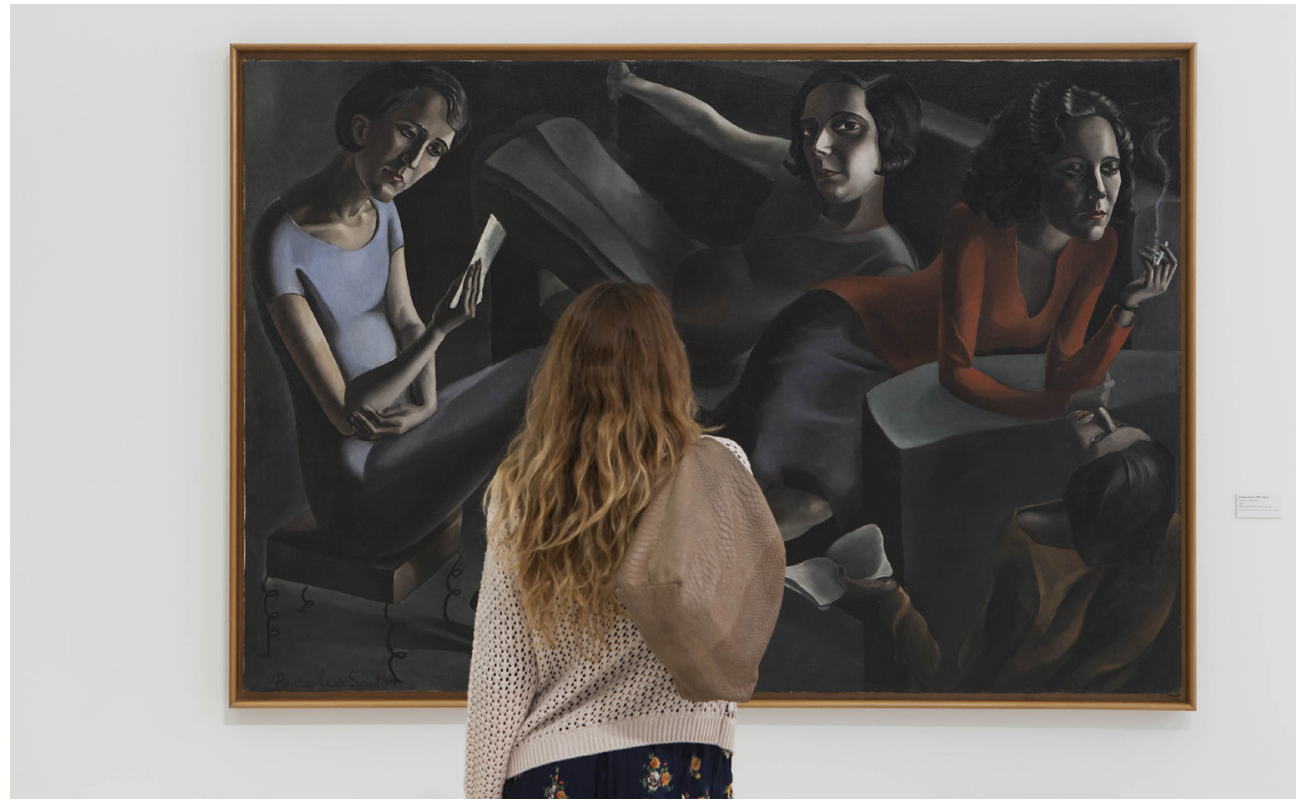

1. Vista de la exposición Jesús Domínguez @ Museo Picasso Málaga género no binario. Cahun también realizó este planteamiento en el campo de la literatura y en el de su propia vida pues, como es sabido, su nombre artístico Claude, al igual que el de su compañera Marcel, es nombre tanto de hombre como de mujer en francés. Por consiguiente, podemos entender esta propuesta fotográfica, literaria y vital como un intento por parte de la artista de construir un nuevo cuerpo, el cuerpo de un tercer género que no fuera ni el masculino ni el femenino.

Señala Paul Éluard en uno de sus poemas que «hay otros mundos, pero están en este». $Y$ ese es el hilo argumental de la segunda sección de esta exposición en la que encontramos obras de artista como Toyen, Kay Sage o Maruja Mallo. Esos otros mundos bien podrían ser los que Kay Sage recreó en obras como Peligro, zona en construcción que se muestra en las salas del Palacio de Buenavista y que demuestran una excelente técnica ilusionista al servicio de la creación de paisajes remotos con un horizonte desprovisto de figuras humanas. El estilo de Sage ha sido emparentado con el de su compañero Yves Tanguy o con el de Giorgio de Chirico, cuya obra conoció en la exposición surrealista internacional de 1938.

En la misma sala también encontramos otros mundos como el que recrea Maruja Mallo en la serie de Las Verbenas, realizada entre 1927 y 1928. La artista gallega imagina un particular mundo que recuerda al de las verbenas y ferias populares y en el que tienen cabida marineros cuyos rostros se deforman ante el espejo, gigantes y cabezudos, y en el que las referencias a Goya o Velázquez son evidentes. También se observa el interés de Maruja por las diferentes culturas, interés que desarrollará durante su exilio.

Si no puedo persuadir a los dioses del cielo, moveré a los de los infiernos. Con este pasaje de la Eneida de Virgilio inicia Sigmund Freud La interpretación de los sueños. Precisamente es el mundo de lo onírico el protagonista de la tercera sección de la exposición, en la que encontramos obras como Eine kleine Nachtmusik de Dorotea Tanning en las que se recrean espacios que remiten al mundo de los sueños. La artista estadounidense pone su técnica académica al servicio de una visión mágica del mundo. Muestra lo que parece ser el pasillo de un hotel con puertas numeradas, la más alejada de las cuales está lo suficientemente abierta como para mostrar una potente luz saliendo de su interior. Un girasol gigante y trozos de su tallo rasgado descansan en el rellano. Dos pétalos caídos se encuentran más abajo de las escaleras y un tercero es sujetado por una muñeca apoyada contra una de las puertas. La muñeca es real y usa ropa similar a la de la chica que tiene cerca. El estado destrozado de la ropa que llevan tanto la muñeca como la niña sugiere 
2. Vista de la exposición Jesús Domínguez @ Museo Picasso Málaga

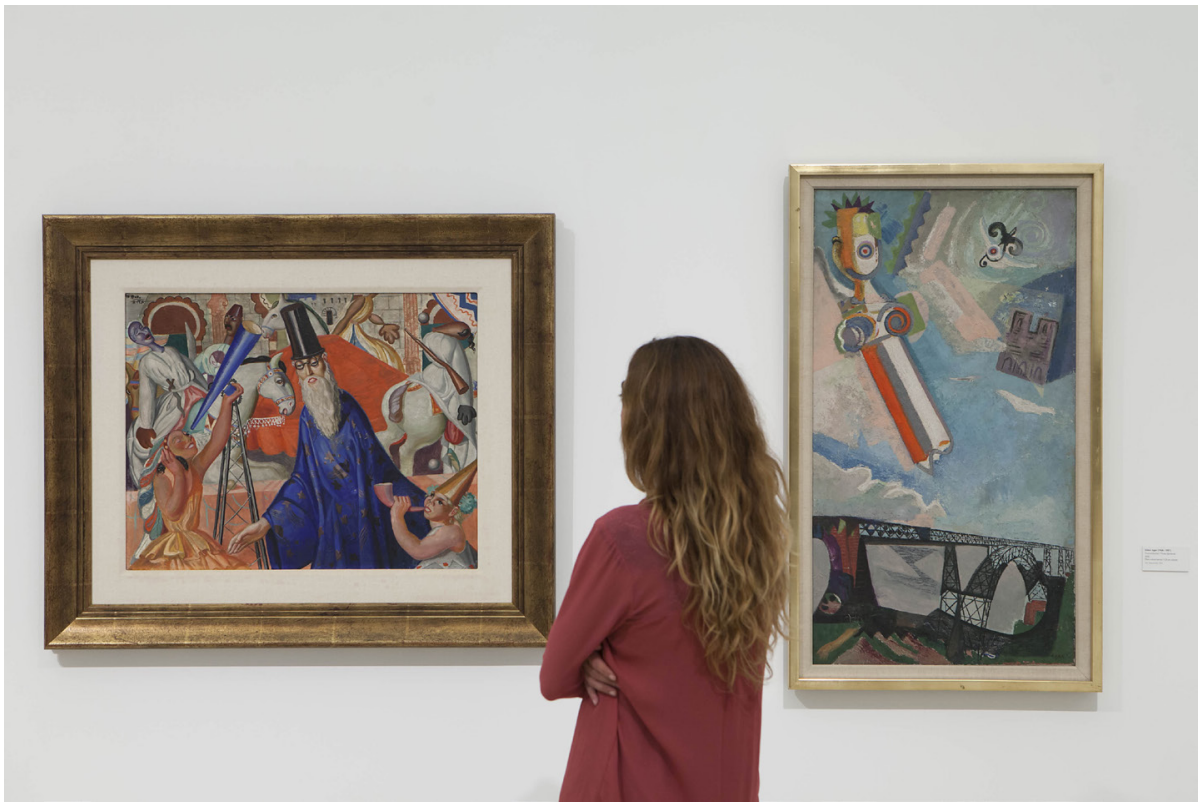

que ha habido algún tipo de lucha o encuentro con fuerzas poderosas, y el pelo largo de la niña fluye hacia arriba como si hubiera sido golpeado por una ráfaga de viento inmensamente potente. Esta obra es un buen ejemplo del intento que realizaron muchos artistas vinculados al surrealismo por describir visualmente el mundo de lo onírico.

En esta tercera sección también encontramos los interesantes dibujos de Unica Zürn que dan cuenta de la función del dibujo para anudar el registro de lo imaginario en casos de esquizofrenia. En ese sentido, podemos plantear que la función que el dibujo tenía para Zürn era similar a la que tenía la escritura para James Joyce según la interpretación que hace Jacques Lacan en el Seminario 23 El Sinthome. En los últimos años, textos de la artista alemana como El trapecio del destino y otros cuentos, Primavera sombría y El hombre jazmín han sido reeditados en castellano, lo que ha supuesto un mejor conocimiento de su faceta literaria así como una mayor difusión de la misma.

La cuarta sección de la exposición se articula en torno a la idea de «El vértigo de Eros». La historiografía del arte suele citar El perro andaluz como la primera película surrealista, olvidando, en muchos casos, que un año antes la directora de cine francesa Germaine Dulac había estrenado La concha y el reverendo con guion de Antonin Artaud. Como recuerda el comisario de la exposición, esta obra desató fuertes críticas de los surrealistas, llegando Artaud a renegar de ella y proferir insultos a Dulac en plena proyección. La presencia de esta película en la exposición demuestra la importancia que el cine tenía para la expresión de las poéticas surrealistas. De hecho, la fotografía y el cine eran los medios más adecuados para captar lo que Walter Benjamin denominó el «inconsciente óptico», es decir, aquello que el «ojo consciente» no puede captar. Dicho de otro modo, el cine era una de las vías regias al inconsciente.

La exposición se cierra con obras como Tertulia de Ángeles Santos en la que encontramos, entre un grupo de cuatro mujeres reunidas en una estrecha composición, una figura central que mira al espectador y le interpela directamente, en un juego de miradas que cobra sentido a través del título de la sección: «yo es otra». Es decir, que el espejo que el Otro nos devuelve configura nuestra subjetividad. Resulta curioso que durante los días en los que esta exposición ocupaba las salas del Palacio de Buenavista, a pocos metros, se proyectaba la película Call me by your name, escrita por James Ivory y dirigida por Luca Guadagnino, y que precisamente plantea la sugerente idea de verse a uno mismo a través del otro.

Javier Cuevas del Barrio 